\title{
Date Fruit Extract (Phoenix dactylifera, Ajwa) Modulates NK Cells and TNF- Alpha in DMBA-Induced Mammary Cancer Sprague-Dawley Rats
}

\author{
Rehab Mohammed Mustafa Elhemeidy ${ }^{1}$, Diana Lyrawati ${ }^{2 *}$, Edi Widjajanto ${ }^{3}$ \\ ${ }^{1}$ Faculty of Medicine, Brawijaya University, Malang 65145, Indonesia \\ ${ }^{2}$ School of Pharmacy, Faculty of Medicine, Brawijaya University, Malang 65145, Indonesia \\ ${ }^{3}$ Department of Clinical Pathology, Faculty of Medicine, Brawijaya University, Malang 65145, Indonesia
}

Article history:

Submission April 2018

Revised May 2018

Accepted June 2018

*Corresponding author:

E-mail:

diana.l@ub.ac.id

\begin{abstract}
Cellular immune system is one of anti-tumor target development. NK cells, one of major components of antitumor innate immune responses, are frequently decreased functionally during breast cancer progression, whereas TNF-alpha changes from anti-tumor into pro-tumorigenesis and its level increases with advancing cancer. In this study, we investigated the immunomodulatory effects of Ajwa date fruit extract to determine whether it stops the progression of breast cancer. Using rats induced with single dose $20 \mathrm{mg}$ DMBA subcutaneously, we examined whether administration of Ajwa date fruit (Phoenix dactylifera) extract (at $400,800 \mathrm{mg} / \mathrm{kg}$ body weight/d) post-DMBA induction for 30 days modulate NK cells, TNF-alpha, and development of breast cancer. ELISA, FACS, immunohistochemistry, and histologic observation were employed. Compared to positive control group (DMBA-induced only), we showed that the Ajwa date fruit extract normalize the level of circulatory CD161 NK cells and breast tissue TNF-alpha, cell size and proliferation, and improve overall survival rates. Ajwa date fruit extract may be used to modulate NK cells and TNF-alpha against progression of breast cancer. Further studies are required to develop date fruit extract as anticancer in human, whether as single or adjunct therapy to standard management of breast-cancer.
\end{abstract}

Keywords: Ajwa, dates, cancer, mammae, immunomodulatory

\section{Introduction}

NK cells, one of major components of anti-tumor innate immune responses, are frequently decreased functionally during breast cancer progression [1], whereas TNF-alpha changes from antitumor into pro-tumorigenesis and its level increases with advancing cancer [2]. NK cells and TNF-alpha are among cellular immune system targets in anti-tumor development.

Others have reported the general immunostimulatory capacities of matured date fruit extract [3]. In particular, Ajwa date fruit extract has been shown to exert anticancer activities, e.g. in vivo in hepatocarcinoma [4]. The anticancer properties are mainly associated with antioxidant and anti-inflammatory of the phytochemical components of the herbs [5, 6]. Ajwa date extract was also in vitro tested in breast adenocarcinoma [7]. The advancing of breast cancer, chemotherapy-resistance, and recurrence involve immune-escape of the breast cancer cells [8]. Thus, in this study, we aimed to determine whether Ajwa date fruit extract could modulate immune system in vivo, in particular alter the NK cells and TNF-alpha levels to stop the progression of breast cancer.

\section{Material and Methods \\ Ajwa date fruit extract}

The Ajwa date fruits were obtained from Madinah, UAE. The pulp of the dried Ajwa fruits was manually separated from the pits and pulverized into powder. About $650 \mathrm{~g}$ of the powder was

\section{How to cite:}

Elhemeidy RMM, Lyrawati D, Widjajanto E (2018) Date Fruit Extract (Phoenix dactylifera, Ajwa) Modulates NK Cells and TNF-Alpha in DMBA-Induced Mammary Cancer Sprague-Dawley Rats. Journal of Tropical Life Science 8 (3): 227 - 235. doi: 10.11594/jtls.08.03.04 
soaked in $2 \mathrm{~L}$ of cold distilled water. After 24 hours, the solution was filtered and lyophilized to dryness, and kept at $4^{\circ} \mathrm{C}$ until used. Ajwa date extract to be given orally to animals was freshly thawed daily.

\section{Animals and treatments}

Female Sprague-Dawley rats aged 50 - 60 days (200 g body weight) were obtained from Central Laboratory of Life Sciences - Animal Supplier, Brawijaya University, Malang, Indonesia. The animals were allowed access to food and tap water ad libitum throughout the acclimatization and experimental periods. Three groups of six rats were treated with $20 \mathrm{mg}$ 7,12-dimethylbenz(a)anthracene (DMBA, Sigma-Aldrich, USA) in 0.5 $\mathrm{mL}$ olive oil, injected subcutaneously into right flank, whereas normal group was given $0.5 \mathrm{~mL}$ olive oil. Rats were palpated weekly to check for tumour appearance. Administration of Ajwa date fruit extract were started orally from week 11 to 14: $400 \mathrm{mg} / \mathrm{kg}$ body weight $/ \mathrm{d}$ in distilled water (group T1); or $800 \mathrm{mg} / \mathrm{kg}$ body weight $500 \mathrm{~g} / \mathrm{d}$ in distilled water (group T2), whereas normal and positive control were not given any extract. Doses used in these experiments were calculated based on previous report [4]. All animals received humane care in compliance with the National Institutes of Health criteria for care of laboratory animals. All treatments were in accordance to standard protocol agreed by Animal Ethics Committee for Health Research, Faculty of Medicine, Brawijaya University (\#115/EC/KEPK-S2/03/2017).

\section{Sample collection}

All animals were sacrificed at the end of week 14 post-DMBA treatment, euthanized by $\mathrm{CO}_{2}$ inhalation. Blood was obtained by cardiac puncture and collected without anticoagulant, then centrifuged at $500 \mathrm{~g}$ for 10 minutes to get serum. Breast tissue were removed, weighed, and cut for evaluation, including for TNF-alpha and histological analysis.

\section{TNF-alpha measurement}

Protein were isolated from breast tissues using RIPA buffer standard protocol [9] and TNF-alpha were measured using ELISA method (R\&D Systems, USA) according to manufacturer's instruction as previously described [10]. Absorbance was recorded at $450 \mathrm{~nm}$. The protein level of tissue su- pernatant was estimated and concentrations of TNF- $\alpha$ expressed as ng/mg of protein.

\section{Evaluation of NK cells}

Isolation of NK cells from PBMC and measurement were performed as previously described [11] using FITC conjugated mouse anti-ratCD161 antibody (Immunotools, Germany) on FACS machine (FACSCalibur).

\section{Histopathological evaluation}

Samples of the breast tissues were fixed in $10 \%$ neutral buffered formalin solutions for $24 \mathrm{~h}$. Standard histopathological techniques were followed for processing the tissue and preparation of paraffin blocks. A qualitative analysis of breast tissue was performed on sections ( $4 \mu \mathrm{m}$ thick) stained with haematoxylin and eosin (H\&E) for histopathological examination and Ki-67 for proliferation index. Sections were observed by using an Olympus CX 21 series microscope and OlyViA image viewer analytical system. Each sample was observed at a magnification of $40 \times$ and $400 \times$. Morphologic observation, cell shape and size, was performed on five fields per section, and determined by two trained investigators who were unaware of the experimental groups. Microscopic images (at least five fields/slide) were analysed using Image J v. 1.45 .

\section{Immunohistochemistry evaluation}

Fixed liver sections on slides were processed for immunohistochemistry evaluation. A primary mouse anti-Ki-67 monoclonal antibody (Immunotools, Germany) was employed in a standard immunostaining protocol $[12,13]$. Colour was developed using DAB-horse radish peroxidase (SigmaAldrich, USA) to produce a brown precipitate. Sections were counterstained with hematoxylin (Sigma-Aldrich, USA). Stained cells were examined microscopically [14] and images recorded as described above.

\section{Statistical analysis}

The results were expressed as means \pm standard deviation. Statistical analyses (GraphPad Prism v.7, GraphPad Inc., CA, USA) were performed using One-way ANOVA followed by Tukey post -hoc test and considered significant at $\mathrm{p}<0.05$. 


\section{Results and Discussion}

\section{Measurement of TNF-alpha of breast tissues}

In this study, rats with breast cancer tissues TNF-alpha level have increased ( $p<0.0001$ ) (Figure 1). Administration of Ajwa date extract whether 400 or $800 \mathrm{mg} / \mathrm{kg}$ BW/d normalised TNFalpha level $(p=0.0732$ and $p>0.9999$, respectively). TNF-alpha levels (means \pm SD) were $43.24 \pm 3.417 ; 56.95 \pm 4.128 ; 45.04 \pm 0.6029$; and $43.29 \pm 1.551 \mathrm{ng} / \mathrm{L}$ for normal; DMBA only; Ajwa treatment 400 and $800 \mathrm{mg} /$ body weight/d groups, respectively.

\section{Measurement of circulatory NK cells}

In this study, DMBA-induced breast cancer rats showed decreased circulatory NK cells number ( $p=0.003)$, and Ajwa date extract could increase NK cells number more than that of normal group $(\mathrm{p}=0.0002)$ (Figure 1). Percentages of NK cells (mean \pm SD) were $30.6 \pm 26.7 ; 27.01 \pm 18.94$; $54.91 \pm 13.95$; and $89.54 \pm 5.24 \%$ for normal; DMBA only; Ajwa treatment 400 and 800 $\mathrm{mg} /$ body weight/d groups, respectively.

\section{Histopathological evaluation}

Slides were observed based on the morphology, curvature of terminal duct-lobule which include the acini, ducts surrounded by epithelial and myoepithelial cells, basement membrane, the lumen and fatty tissue. Compared to normal group, administration of DMBA resulted in morphological changes (Figure 2, Table 1). Rats in DMBA only group lost normal breast cell features, the lumen of the duct was filled with atypical proliferative cells. The basophilic proliferative cells also damaged the basement membrane and infiltrated into the fibrous connective tissue, forming invasive ductal carcinoma. Groups treated with Ajwa date showed morphology similar to normal cellular structures, ductus surrounding with epithelial cells, acini and fat cells, albeit some fibrosis also detected.

\section{Immunohistochemistry Ki-67 evaluation}

In the present study, we determined whether Ajwa extract could inhibit proliferation of breast cells following DMBA induction. Using immunohistochemistry, we analysed cells expressing Ki67 using antibody against rats Ki-67 (Figure 3). Administration of Ajwa date extract decreased Ki67 stained breast cancer. Compared to the DMBA only group (60 - 64\% cells Ki-67 stained showed dark brown color), Ajwa date extract treatment resulted in decreased breast cell proliferation (cells showed blue color).

\section{Evaluation of cell size}

DMBA only induction resulted in bigger cell size $(9.17-15.66 \mu \mathrm{m})$ compared to normal group $(3.03-4.17 \mu \mathrm{m})(\mathrm{p}<0.0001)$, whereas treatment with Ajwa date extract could renormalized the cell size, in particular at $800 \mathrm{mg} / \mathrm{kg}$ body weight $/ \mathrm{d}$ (3.32 - $5.25 \mu \mathrm{m})$ (Figure 4). The nuclear cytoplasmic ratio in normal cell approximately between 1 : $5-1: 6$, in cancer cell following DMBA induction 1: 1 with large cell size, and after treatment with Ajwa date fruit extract back to $\sim 14-1: 6$.

\section{Overall survival rates}

DMBA induction resulted in decreased survival rates. In Ajwa date groups, rats died only before Ajwa date extract treatment. After treatment with Ajwa extract, none of the rats died. Ajwa date extract could improve survival rate of rats induced with DMBA (Figure 5), however did not reach statistical significance $(p=0.21)$.

In this study, we used DMBA to induce chronic liver breast cancer in Sprague-Dawley rats then treated with Ajwa date extract to see whether administration of Ajwa extract could prevent the progression of breast cancer. DMBA following metabolism generated many mutagenic metabolites. DMBA is a highly lipophilic molecule, thus, DMBA can accumulate at the breast adipose tissue or epithelium contact [15]. After metabolic activation in the mammary gland, the carcinogenic metabolites interact with rapidly proliferating cells, forming DNA adducts.

The subsequent mutations contribute in cells transformation into malignancy [15]. SpragueDawley (SD) rats were used because they are DMBA-sensitives mainly at $55-60$ days of age [15]. As this study showed, DMBA administration resulted in breast cancer, whereas treatment with Ajwa date extract may stop the progression of breast cancer as shown in histopathological data and Ki-67 staining's (Figure 2 and 3).

The results in this study showed that TNF-alpha values of group treated with DMBA alone was high, whereas TNF-alpha profiles in breast tissue of DMBA-induced rats which subsequently treated with Ajwa date extract did not differ 

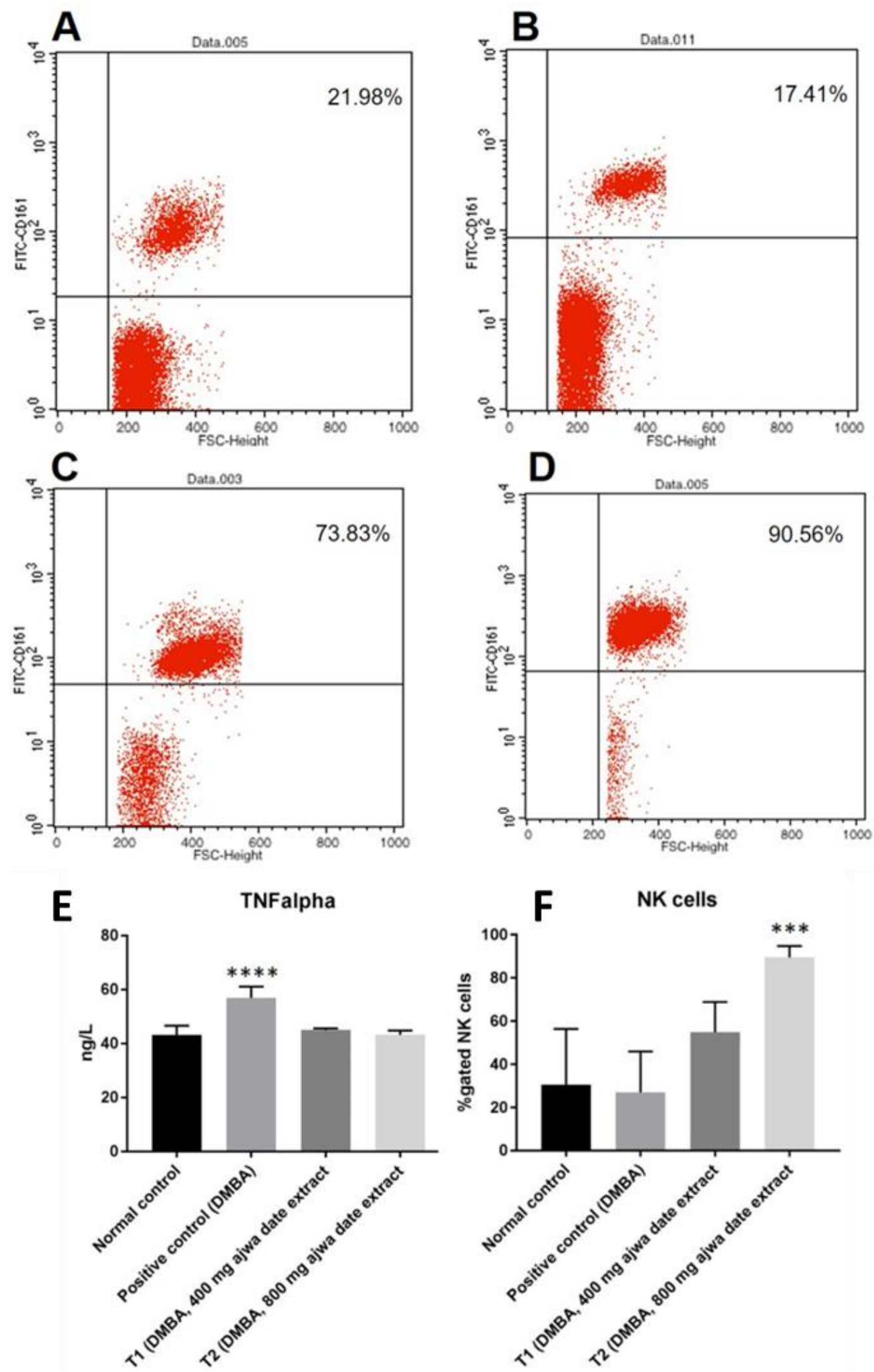

Figure 1. Ajwa date fruit extract improved TNF-alpha level and NK cell number in breast cancer groups. FACS of NK cells showed that in DMBA-only group number of NK cells decreased (B) whereas administration of 400 or $800 \mathrm{mg}$ Ajwa date extract increased NK cells (C, D). Graphs showed that Ajwa date extract normalised TNF-alpha level (E) and increased number of NK cells (F). Asterisks indicate that values statistically different compared to that of normal group. 


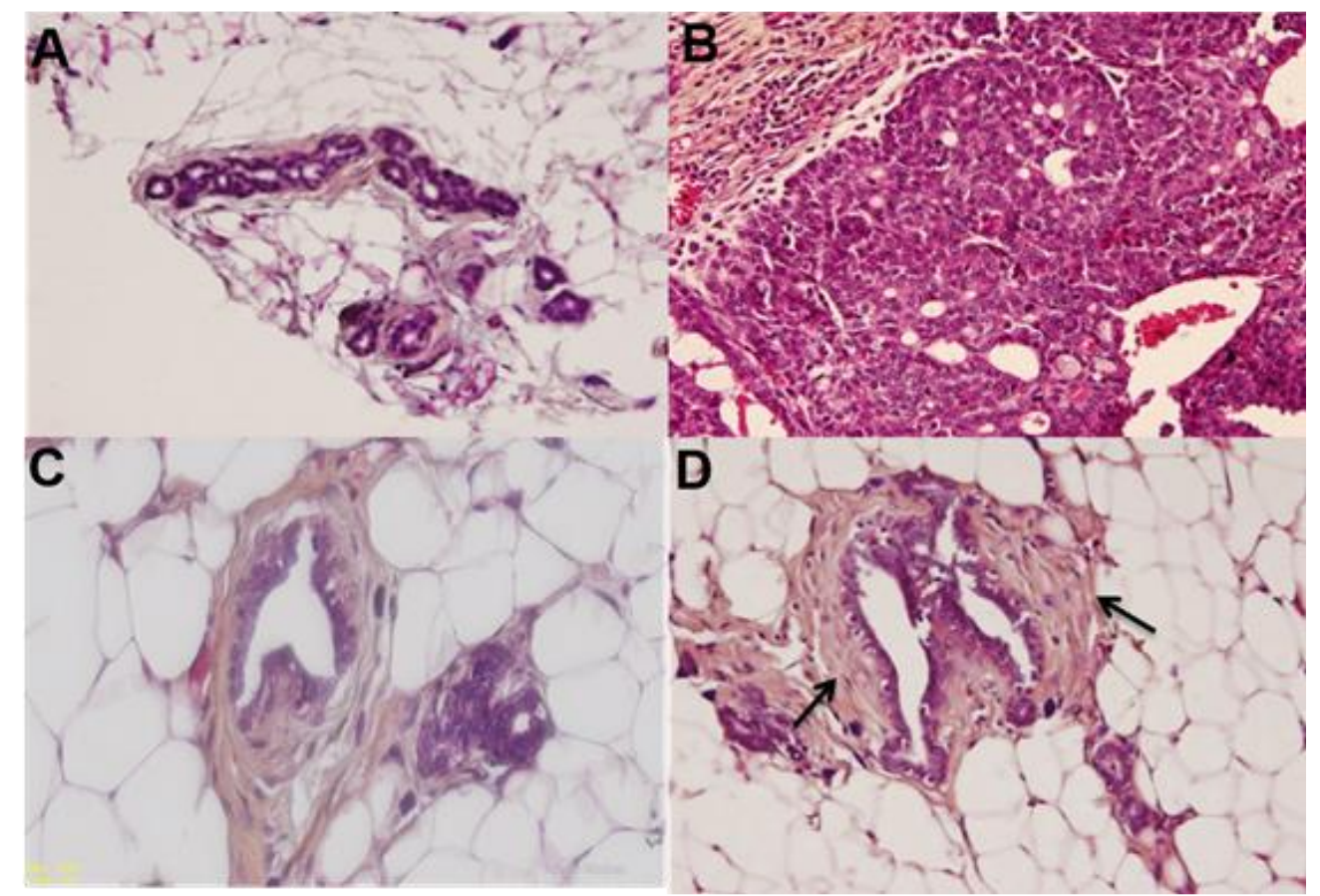

Figure 2. Histopathological observation of breast cells following DMBA-induction with or without Ajwa date extract. DMBA induction resulted loss of normal cell features (A, normal group, B, DMBA only induction). Ajwa date extract normalised morphological features of cells in rats with DMBA induction (C, $400 \mathrm{mg}$ Ajwa date extract, and D, $800 \mathrm{mg} / \mathrm{kg} \mathrm{BW} / \mathrm{d}$ Ajwa date extract). Arrows indicates fibrotic tissues (D). Original magnification, $400 \times$.

significantly with the normal group. On the contrary, the number of circulatory NK cell in DMBA alone group was low, whereas Ajwa date treatment groups showed higher number than both normal and DMBA alone groups. Such data indicates that treatment with Ajwa date extract could normalised TNF-alpha in breast tissue of DMBA-induced rats while increasing CD161 NK cells. Ajwa date properties as antioxidant, anti-inflammatory [5, 6, 16] and anticancer [4] may play roles in TNF-alpha modulation. Many date extracts have been characterised physicochemically and tested for their antioxidant capacities as direct free radical scavengers and/or improve the antioxidant enzymes level/activities [17]. Ajwa date extract serves also as anticancer by inhibiting cancer cell proliferation [18] and modulation of pro-inflammatory cytokine/chemokines expression and inhibiting COX-2 inflammatory pathways [5, 18]. Controlling the mutagenic and pro-inflammatory substances including containment of free radical species would result in low level of TNF-alpha in tissue. TNF alpha expressing tumours up-regu- lated Fas (CD95) expression and inhibited the expression of tumour metastasis associated molecule CD44v3 [19]. High level of TNF-alpha, however is not always good for cells/tissue. Tumour necrosis factor-alpha is also a potent endogenous mutagen that promotes cellular transformation [20], cancer growth and invasion [21].

Ajwa date extract could also regulate proliferation, migration, differentiation and maturation of hematopoietic cells, e.g. red blood cells and platelet [22]. The later properties of Ajwa date may explain the increase number of CD161 NK cells observed in the present study. During carcinogenesis, NK cells, serving immune-surveillance, should recognise then lyse tumour cells [23]. The ability of NK cells to lyse target cell is acquired at specific stage of differentiation and phenotypically identifiable as CD161+ [24]. The NK cytolytic function links also to TNF-alpha which upregulating target cells ICAM-1 expression, hence facilitating conjugation between target cells and NK cells [25]. CD161 is an inhibitory surface receptor in NK cells, can also be found in T-cells 
Table 1. Histopathological analysis of hematoxylin-eosin stained cells following DMBA- induction and Ajwa date extract treatments

\begin{tabular}{llll}
\hline & Normal mammary tissue & \multicolumn{1}{c}{ Cancer mammary tissue } & \multicolumn{1}{c}{ After treatment } \\
\hline Structure & Composed of terminal & Loss of normal cell & No cancer cell \\
& duct-lobule (TDL) units & features,and specialisation & \\
and fatty tissue & and functional & \\
& & differentiation &
\end{tabular}

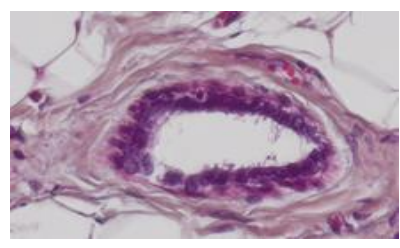

Shape Regular shape, small,uniform shaped nuclei, relatively large cytoplasmic volume

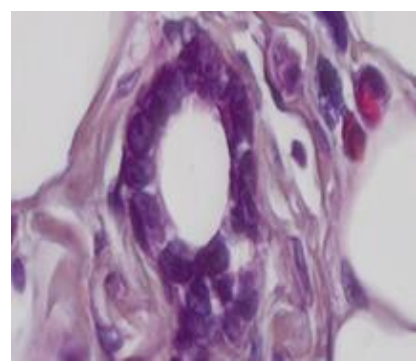

Size

Conformity in cell size

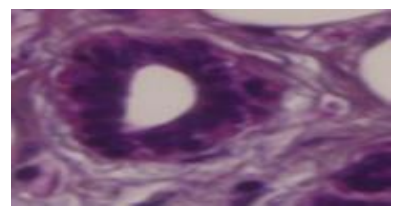

HE-stain Normal cell colour

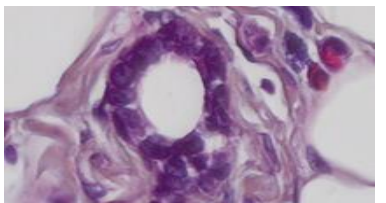

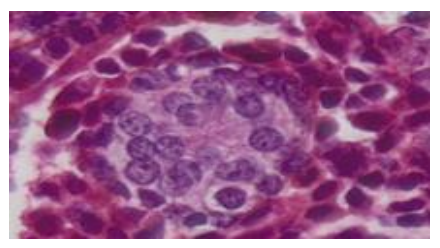

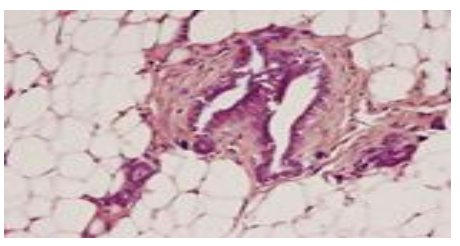

Irregular shape, large, var- $\quad$ No cancer cell iable shaped nuclei, relatively small cytoplasmic volume
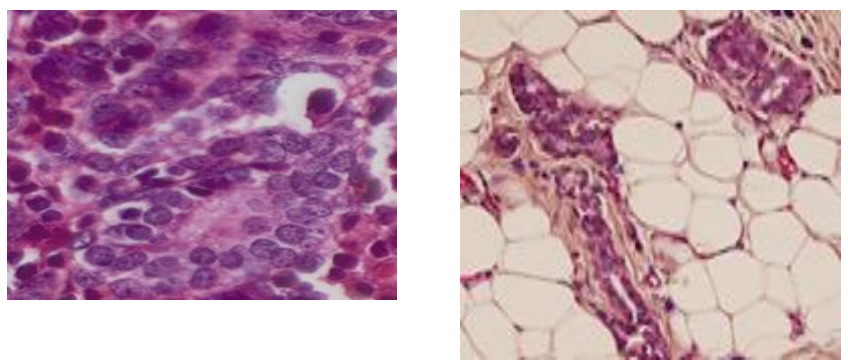

Back to normal size

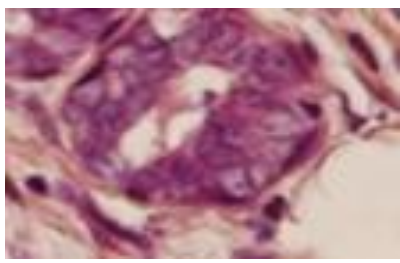

Back to normal cell colour cell
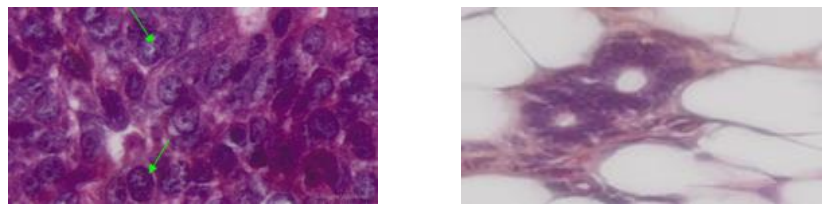


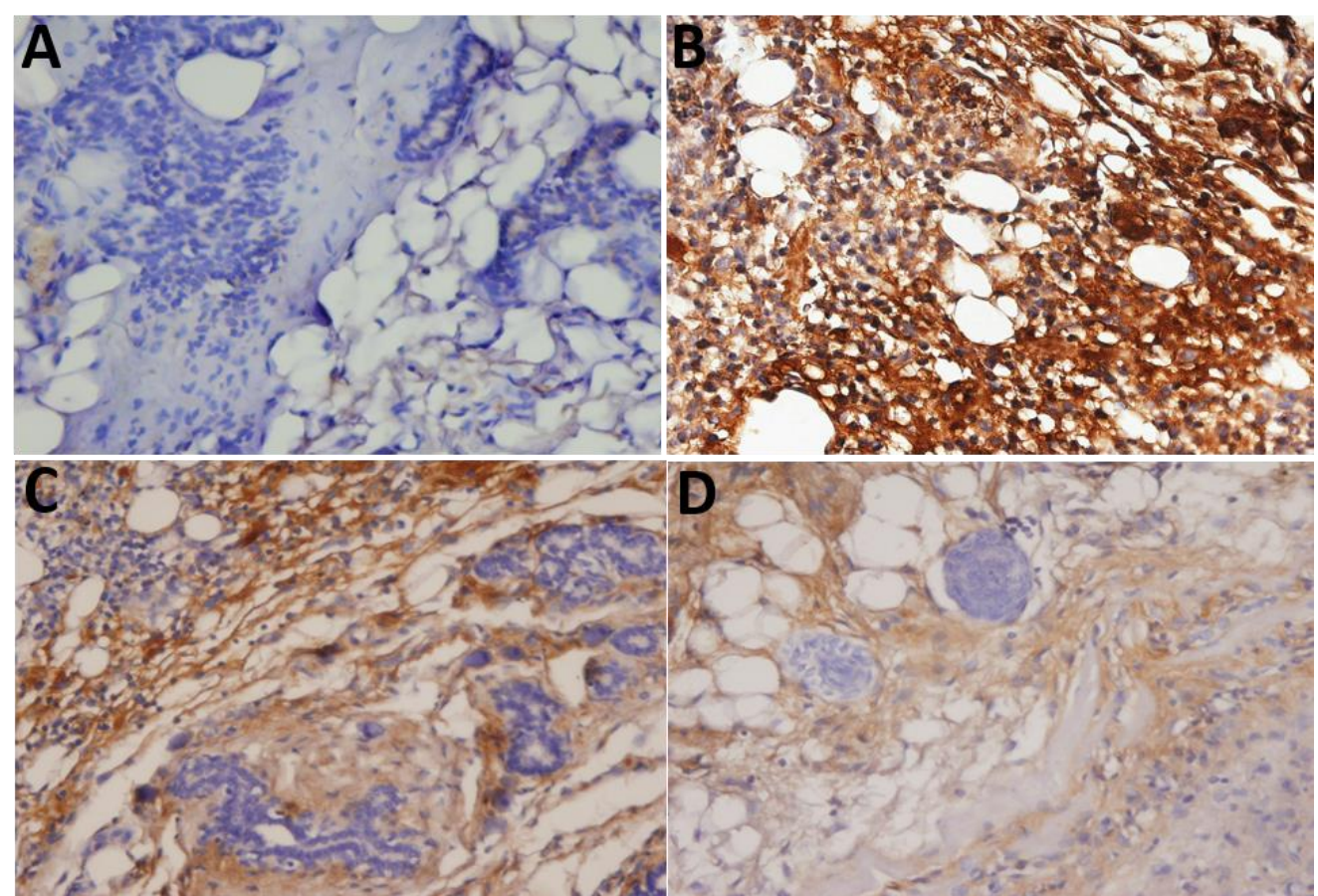

Figure 3. Histopathological observation of breast cells following DMBA-induction with or without Ajwa date extract. DMBA induction resulted in high level of Ki-67 stained cell (high proliferative index) (B) compared to that of normal group (A). Ajwa date extract normalised Ki-67 expression in breast cells in rats with DMBA induction (C, $400 \mathrm{mg}$ Ajwa date extract, and D, $800 \mathrm{mg} / \mathrm{kg}$ BW/d Ajwa date extract). Original magnification, $400 \times$.

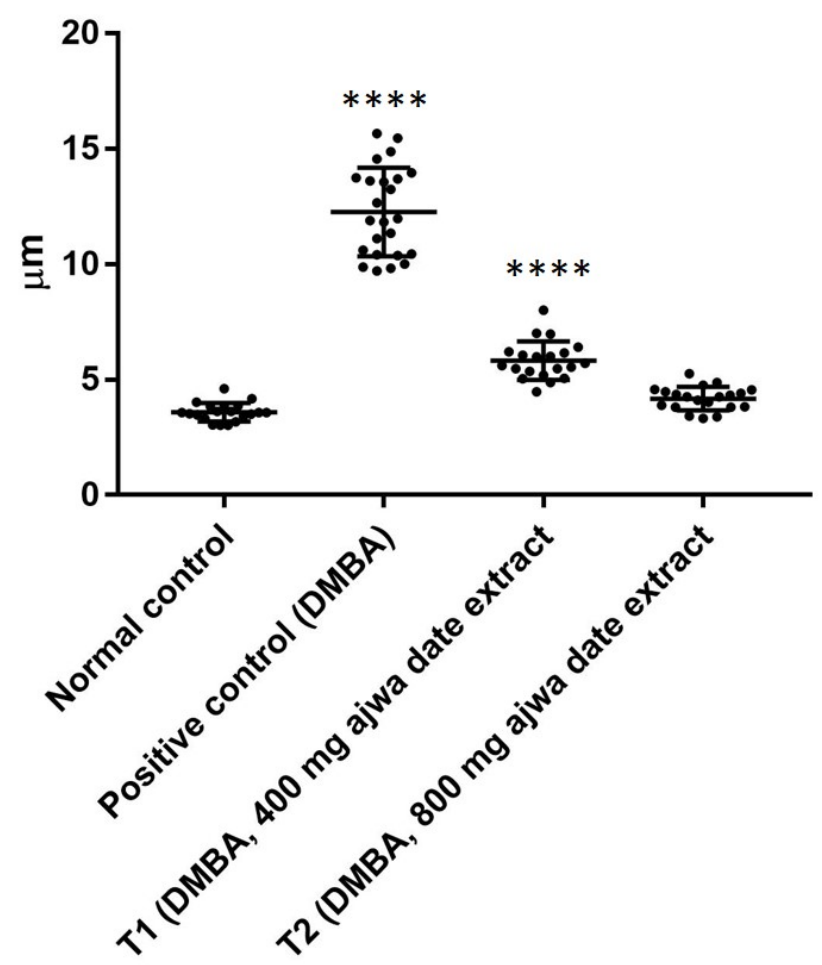

Figure 4. Cell size. DMBA induction resulted in bigger cell size compared to normal group $(\mathrm{p}<0.0001)$, whereas Ajwa date extract at $800 \mathrm{mg} / \mathrm{kg}$ BW/drenormalized the cell size. 


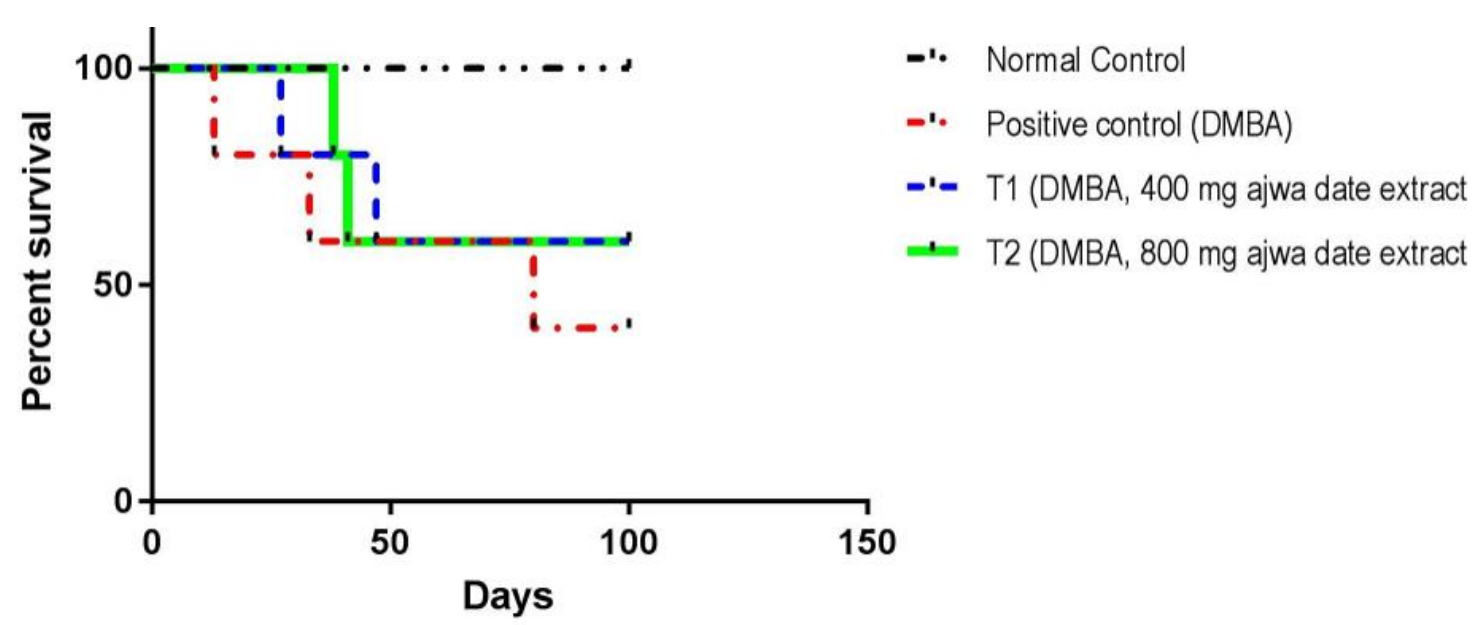

Figure 5. Overall survival. DMBA induction resulted in decreased survival rates. Ajwa date treatment, started on day 70 (10 weeks post-DMBA), could improve survival rate of rats induced with DMBA.

subsets, functions as immunosurveillance by recognising tumour cells not expressing MHC class I and destroying them [24]. It is associated with a good outcome in cancer patients [26]. It may be related to components of the extracellular matrix and connective-tissue growth factor, and a mediator of fibrosis that promotes the synthesis of the matrix. Histologically, presence of fibrosis following treatment in biopsied cancerous tissues is one of markers associated with good clinical outcomes [27].

Combination of controlled level of TNF-alpha and CD161 NK cells, in the present study, associated with good histological observation in groups DMBA-induced that treated with Ajwa date extract. The survival curve also supports the protective effect of Ajwa date extract. As Ajwa date contains many compounds including amino acids and monosaccharides[28], treatment with Ajwa extract not only protect from DMBA-induced breast cancer but may also repair the cells. The detail mechanism of such repair remains to be clarified and is important for survival of the breast cancer individuals.

\section{Conclusion}

Current study can be concluded that Ajwa date fruit extract confers anticancer in DMBA-induced breast cancer through the modulation of TNF-alpha and NK cells. Thus, Ajwa date fruit extract could prevent disease progression and may transform cancerous tissue into fibrotic or repaired tissue. Further studies are required to see whether similar effects will be seen in different aetiology such as cancer due to alcohol or viruses.

\section{Acknowledgment}

This study received no funding from other sources. The authors thank Dr.KaryonoMintarum from Laboratory of Anatomical Pathology and Mr.YudaNgatirilLady from Laboratory of Biomedical Sciences, Brawijaya University, for anatomical pathology and histology expertise and technical assistance for FACS, respectively.

\section{References}

1. Waldhauer I, Steinle A (2008) NK cells and cancer immunosurveillance. Oncogene 27: 5932 - 5943. doi: 10.1038/onc.2008. 267.

2. Kottke T, Evgin L, Shim KG et al. (2017) Subversion of NKcell and TNF $\alpha$ immune surveillance drives tumor recurrence. Cancer Immunology Research 5 (1): 1029 - 1045. doi: 10.1158/ 2326-6066.

3. Karasawa K, Uzuhashi Y, Hirota M, Otani H (2011) A matured fruit extract of date palm tree (Phoenix dactylifera L.) stimulates the cellular immune system in mice. Journal of Agricultural and Food Chemistry 59 (20): 11287 - 11293. doi: 10.1021/jf20292 25.

4. Khan F, Khan TJ, Kalamegam G et al. (2017) Anti-cancer effects of Ajwa dates (Phoenix dactylifera L.) in diethylnitrosamine induced hepatocellular carcinoma in Wistar rats. MC Complementary and Alternative Medicine 17: 418 - 427. doi: 10.1186/s12906-017-1926-6.

5. Zhang CR, Aldosari SA, Vidyasagar PS et al. (2013) Antioxidant and anti-inflammatory assays confirm bioactive compounds in Ajwa date fruit. Journal of Agricultural and Food Chemistry 61 (24): 5834 - 5840. doi: 10.1021/jf401371v.

6. Baliga MS, Baliga BRV, Kandathil SM et al. (2011) A review 
of the chemistry and pharmacology of the date fruits (Phoenix dactylifera L.). Food Research International 44 (7): 1812 - 1822 doi: 10.1016/j.foodres.2010.07.004.

7. Khan F, Ahmed F, Pushparaj PN et al. (2016) Ajwa date (Phoenix dactylifera L.) extract inhibits human breast adenocarcinoma (MCF7) cells in vitro by inducing apoptosis and cell cycle arrest. PLoS One 11: e0158963. doi: 10.1371/journal.pone.0158 963.

8. Mamessier E, Sylvain A, Thibult ML et al. (2011) Human breast cancer cells enhance self tolerance by promoting evasion from NK cell antitumor immunity. Journal of Clinical Investigation 121 (9): 3609 - 3622. doi: 10.1172/JCI45816.

9. Valkova N, Yunis R, Mak SK et al. (2005) Nek8 mutation causes overexpression of galectin-1, sorcin, and vimentin and accumulation of the major urinary protein in renal cysts of jck mice. Molecular and Cellular Proteomics 4: 1009 - 1018. doi 10.1074/mcp.M500091-MCP200.

10. Dinarshanty D, Noorhamdani AS, Kawuryan SL, Wibowo S (2017) TNF- $\alpha$ and interleukin-6 levels in clinical early onset neonatal sepsis toward acute liver injury. Jurnal Kedokteran Brawijaya 29 (3): 216 - 222. doi: 10.21776/ub.jkb.2017.029.03. 6.

11. Xue M, Liang H, Tang Q et al. (2017) The Protective and immunomodulatory effects of fucoidan against 7,12-dimethyl benz[a]anthracene-induced experimental mammary carcinogenesis through the PD1/PDL1 signaling pathway in rats. Nutrition and Cancer 69 (8): 1234 - 1244. doi: 10.1080/01635581. 2017.1362446.

12. Hofman F (1996) Current protocols in immunology. New York, John Wiley and Sons.

13. Alvarado A, Lopes AC, Faustino-Rocha AI et al. (2017) Prognostic factors in MNU and DMBA-induced mammary tumors in female rats. Pathology - Research and Practice 213 (5): 441 446. doi: 10.1016/j.prp.2017.02.014.

14. Tuncer E, Unver-Saraydin S, Tepe B et al. (2013) Antitumor effects of Origanum acutidens extracts on human breast cancer. Journal of B.U.ON.: Official Journal of the Balkan Union of Oncology 18 (1): 77 - 85.

15. Kerdelhué B, Forest C, Coumoul X (2016) Dimethyl Benz(a)anthracene: A mammary carcinogen and a neuroendocrine disruptor. Biochimie Open 3: 49 - 55. doi: 10.1016/j.biopen.2016.09. 003.

16. Al-Yahya M, Raish M, AlSaid MS et al. (2016) 'Ajwa' dates (Phoenix dactylifera L.) extract ameliorates isoproterenol-induced cardiomyopathy through downregulation of oxidative, inflammatory and apoptotic molecules in rodent model. Phytomedicine 23 (11): 1240 - 1248. doi: 10.1016/j.phymed.2015.10. 019.

17. Al Harthi SS, Mavazhe A, Al Mahroqi H, Khan SA (2015) Quantification of phenolic compounds, evaluation of physicochemical properties and antioxidant activity of four date (Phoe nix dactylifera L.) varieties of Oman. Journal of Taibah University Medical Sciences 10 (3): 346 - 352. doi: 10.1016/j.jtumed. 2014.12.006.

18. Zhang CR, Aldosari SA, Vidyasagar PSPV et al. (2017) Healthbenefits of date fruits produced in Saudi Arabia based on in vitro antioxidant, anti-inflammatory and human tumor cell proliferation inhibitory assays. Journal of the Saudi Society of Agricultural Sciences 16 (3): 287 - 293. doi: 10.1016/j.jssas.2015.09. 004.

19. Li Q, Li L, Shi W et al. (2006) Mechanism of action differences in the antitumor effects of transmembrane and secretory tumor necrosis factor-alpha in vitro and in vivo. Cancer Immunology Immunotherapy 55 (12): 1470 - 1479. doi: 10.1007/s00262006-0150-x

20. Yan B, Wang H, Rabbani ZN et al. (2006) Tumor necrosis factor-alpha is a potent endogenous mutagen that promotes cellular transformation. Cancer Research 66 (24): 11565 - 11570. 10.1158/0008-5472.CAN-06-2540.

21. Zhu G, Du Q, Wang X et al. (2014) TNF- $\alpha$ promotes gallbladder cancer cell growth and invasion through autocrine mechanisms. International Journal of Molecular Medicine 33 (6): 1431 1440. doi: 10.3892/ijmm.2014.1711.

22. Mallhi TH, Qadir MI, Ali M et al. (2014) Review: Ajwa date (Phoenix dactylifera)- an emerging plant in pharmacological research. Pakistan Journal Pharmaceutical Science 27 (3): 607 616.

23. Vivier E, Tomasello E, Baratin M et al. (2008) Functions of natural killer cells. Nature Immunology 9: 503 - 510. doi: 10.1038/ni1582

24. Zamai L, Ahmad M, Bennett IM et al. (1998) Natural killer (NK) cell-mediated cytotoxicity: Differential use of TRAIL and fas ligand by immature and mature primary human NK cells. The Journal of Experimental Medicine 188 (12): 2375 - 2380. doi: $10.1084 /$ jem.188.12.2375

25. Wang R, Jaw JJ, Stutzman NC et al. (2012) Natural killer cellproduced IFN- $\gamma$ and TNF- $\alpha$ induce target cell cytolysis through up-regulation of ICAM-1. Journal of Leukocyte Biology 91 (2): 299 - 309. doi: 10.1189/jlb.0611308.

26. Rosenwald A, Wright G, Chan WC et al. (2002) The Use of molecular profiling to predict survival after chemotherapy for diffuse large-B-cell lymphoma. New England Journal of Medicine 346: 1937 - 1947. doi: 10.1056/NEJMoa012914.

27. Park CK, Jung WH, Koo JS (2016) Pathologic evaluation of breast cancer after neoadjuvant therapy. Journal of Pathology Translational Medicine 50 (3): 173 - 180. doi: 10.4132/jptm.20 16.02.02.

28. Ali HSM, Alhaj OA, Al-Khalifa AS, Brückner H (2014) Determination and stereochemistry of proteinogenic and non-proteinogenic amino acids in Saudi Arabian date fruits. Amino Acids 46 (9): 2241 - 2257. doi: 10.1007/s00726-014-1770-7. 
This page is intentionally left blank. 